\section{The Last Rain Forests}

Edited by Mark Collins

Mitchell Beazley, London, 1990, 200pp., HB £17.99

Rain forest conservation issues are complex and difficult to comprehend in their entirety. Some concerns are passionately advocated, while others are often skated over, further distorting, complicating and ultimately obscuring the problems while deforestation continues apace. The Last Rain Forests provides an antidote; this is no polemic but a measured, comprehensive and authoritative overview. It is, furthermore, interestingly written and extremely informative, through its lavish illustration no less than its text.

The way that the different aspects of rain forest conservation are teased apart, clearly presented, and fitted back into the whole is the sign of an editor who is a master of his subject. And this is only half the book; the other half consists of large-scale maps of the world's rain-forest regions and additional information about them. Anyone familiar with the situation on the ground in any given region may be able to find points of detail to quibble about-forest patches missing or degraded areas included-but this is hardly important. These are the most accurate large-scale maps of the world's rain forests that are available and their production is a great achievement.

The Last Rain Forests is a valuable publication, the best general book on the subject that is available.

\section{Dolphins: Their Life and Survival \\ Michael Donoghue and Annie Wheeler \\ Blandford, London, 1990 (in}

association with David

Bateman Ltd, Auckland), 119pp., HB $£ 14.95$

Public interest in whales and dolphins has never been greater, yet how many people have ever even seen one? The same goes for otters. There is also a lot of interest in tropical forests, yet relatively few people have ever been to one. It almost seems as though people feel more concerned about the conservation of species, the less their own direct personal experience! This anomaly is fostered and perhaps even brought about by a plethora of books and TV programmes, each of which seems to stimulate production of still more on similar subjects. So, do we really need yet another book on cetaceans and if so, what has this one got to commend it?

Well, first it is about dolphins rather than the big whales that dominated cetacean books a decade or more ago. This reflects a welcome trend towards studying cetaceans for their own sake and as highly intelligent creatures, rather than just killing them for dogfood. Second, the smaller species have often been overlooked because of the attention accorded to their leviathan cousins. They have also been overlooked because they live at sea, making them more difficult to investigate than land animals. Yet many of the dolphins are endangered and pose important conservation problems every bit as serious as for terrestrial species.

The main part of this book deals with these dolphin-related conservation issues, including the river dolphins, not just the marine species. There are chapters on the dangers of giant driftnets $(50,000 \mathrm{~km}$ of which are set every night in the fishing season in the North
Pacific), threats from tuna (and other) fishermen, insidious chemical dangers and the issues posed by captive dolphins and their study and use by the military. The first part of the book is a 'who's who' guide to the various threatened species (stretching 'dolphin' a bit to include narwhal, beluga and killer whale!) and their conservation status. There is also a review of the basic biology of these animals and the often moving relationships of individuals with humans. The final section is about legal protection, and conservation efforts, with suggestions about ways in which individuals can help.

The book is detailed, wellwritten and much enhanced by little marginal notes, which amplify background details (e.g. information about diets or diving physiology). There are substantial text boxes, which contain relevant background stories (e.g. telling of the conflicts that have arisen over the taking of dolphins into captivity). There are also many excellent colour plates.

Altogether this is a very worthwhile and useful book. It gives details and brings up to date many of the scattered stories, often mentioned frustratingly 'Briefly' in Oryx. There is certainly room for this book among all the others, and at its price is much better value than some.

Pat Morris.

\section{United Nations List of National Parks and Protected Areas \\ IUCN, Gland, Switzerland and Cambridge, UK, 1990, 284 pp., SB $£ 12.50 / \$ U S 25$}

This list of national parks and protected areas has been extensively revised and updated 
since the 1985 edition. A total of 6940 sites are included covering 6,514,676 sq km and the introduction gives a brief history of the list, explains the criteria for inclusion and the eight categories used for classifying sites of conservation importance.

Additional information is provided on the biogeographical and ecological coverage of protected areas as well as World Heritage Convention natural sites, Biosphere Reserves and Ramsar sites.

\section{IUCN Red List of} Threatened Animals Compiled by the World Conservation Monitoring Centre

IUCN, Gland, Switzerland and Cambridge, UK, 1990, 228 pp., SB $£ 7.50 /$ \$US15

This update of the 1988 Red List lists over 5000 taxa identified by IUCN as threatened with extinction. For each of the 698 mammals, 1047 birds, 191 reptiles, 63 amphibians, 762 fishes and 2250 invertebrates, the scientific and English names are given with the IUCN category as well as a brief description of the animal's range. Apart from the birds, for which the ICBP has now attempted a global review, the numbers given are only minima. Unfortunately many more taxa are threatened but have not been identified unfortunately as such by IUCN and many of these are undescribed. As studies and reviews continue, it will be apparent that many more are threatened.

The guest essay is on the role of captive breeding in the conservation of species, by Dr Nathan Flesness and Dr Tom Foose of the IUCN/SSC Captive Breeding Specialist Group. IUCN Directory of South
Asian Protected Areas

IUCN, Gland, Switzerland and Cambridge, UK, 1990, 320pp., SB E15/\$US30

This is the first in a series of directories on the protected area system of the Indomalayan Realm. It covers Bangladesh, India, Pakistan and Sri Lanka, giving area, population and GNP data for each country and describing policy and legislation relevant to their protected area systems, their administration and management, and key references. Summary lists and maps of protected areas are followed by descriptions of individual properties.

\section{The Handbook of New Zealand Mammals}

Edited by Carolyn M. King Oxford University Press/OUP New Zealand, 1990, 600pp., HB £38.00

This book describes all 46 species of land-breeding mammals that are, or have been, living in the wild in New Zealand. Of this total only 11 are native. Carolyn King has effectively collated the work of 29 authors whose contributions include much material previously unpublished or gathered from inaccessible or widely scattered sources. There is a useful introductory chapter, an identification guide and a key to skulls. The species accounts are set out in a standardized form for easy reference and are furnished with distribution maps and black-and-white photographs (the endpapers contain colour variations among wallabies, fallow deer, possums and ship rats). The adaptation to and effects of each species on the New Zealand environment is discussed. A glossary and 70 pages of references complete this valuable book, which presents all that is known about New Zealand's mammals, identifies the gaps and should stimulate the research needed to fill them.

Editor.

\section{Guide to the Birds of Madagascar Olivier Langrand Yale University Press, 1991, 364 pp., HB £35/\$US40}

A good comprehensive guide to the birds of Madagascar has been needed for some time now. This book fills the gap admirably. More than just an identification guide, its notes on distribution, status, diet, nesting and habitat, along with the general introductory chapters amount to an up-to-date overview of the current body of information on the Madagascan avifauna. Some of these birds have not been recorded for many years (although one, the Madagascar serpent eagle, has since been discovered by an expedition supported by the FFPS Oryx $100 \%$ Fund), others are extremely rare and threatened, and yet others are recorded from a scatter of widely separated localities. The apparent scarcity of some birds may well be a reflection of the thinness on the ground of ornithologists; one trusts that the publication of the guide itself will help the process of filling in the gaps but the author has also included descriptions of birds that are likely to turn up as well as those that have been recorded. For the visitor there is a very useful select list of birding sites, with details of how to reach them and of what might be seen. This is an essential book for anyone visiting Madagascar and interested in birds, however long their visit.

Roger Wilson. 